\title{
UM CASO DE ANEMIA FERROPRIVA DE ETIOLOGIA DESCONHECIDA ASSOCIADA À SÍNDROME DE MUNCHAUSEN
}

\author{
Maribel Pelaez Dóro ${ }^{2}$ \\ Dr. Ricardo Pasquini ${ }^{3}$
}

\begin{abstract}
RESUMO
O artigo relata a experiência clínica de uma paciente que, a priori, recebeu o diagnóstico de Anemia Ferropriva. Posteriormente, também constatou-se nela a presença da síndrome de Munchausen. Apesar das múltiplas internações, exaustivas investigações clínicas e do tratamento de longa data, a paciente apresentou uma evolução atípica da doença, demonstrando-se refratária a qualquer indicação psiquiátrica e à aderência ao tratamento hematológico. O caso demonstra a possibilidade de coexistência entre a doença hematopoética e a síndrome de Munchausen.
\end{abstract}

Palavras-chave: Síndrome de Munchausen x Anemia Ferropriva.

${ }^{1}$ Estudo realizado no Hospital de Clínicas, Curitiba, PR - Serviço de Psicologia do HCPR; Serviço de Hematologia e de Transplante de Medula Óssea do HC-UFPR.

${ }^{2}$ Psicóloga responsável pelo Serviço de Transplante de Medula Óssea; Mestre em Psicologia da Infância e da Adolescência pela UFPR. Rua Adolfo Stedile, 201 80520-540 - Curitiba - PR. E-mail: maripdoro@uol.com.br.

${ }^{3}$ Chefe responsável pelo Serviço de Transplante de Medula Óssea; Professor Titula da UFPR. 


\title{
A CASE OF IRON DEFICIENCY RELATED ANAEMIA, OF UNKNOWN AETIOLOGY, ASSOCIATED WITH MUNCHAUSEN'S SYNDROME
}

\begin{abstract}
SUMMARY
This article describes the clinical experience of a female patient who, a priori, was diagnosed as suffering from anaemia caused by lack of iron. Later, the patient was also observed to be suffering from Munchausen's syndrome. Despite repeated spells in hospital, exhaustive clinical investigations and treatment over a long period of time, the disease developed atypically in the patient who was resistant to any psychiatric indication or to haematological treatment. The case has shown the possibility of the coexistence of the haematogenous disease and Munchausen's syndrome.
\end{abstract}

Key-word: Munchausen's Syndrome x Iron Deficiency.

\section{INTRODUÇÃO}

$O$ relato a seguir refere-se a um caso de síndrome de Munchausen, de uma paciente da clínica de hematologia do Hospital de Clínicas de Curitiba - PR.

No Manual Diagnóstico e Estatístico de Transtornos Mentais (DSM-IV), esta síndrome recebeu a nomenclatura de Transtorno Factício (300.19), cujos sinais e sintomas são predominantemente físicos, estando presente um desejo intencional de assumir o papel de enfermo (DSM-IV, 1994; Bauer \& Boegner, 1996).

O diagnóstico de Anemia Ferropriva de etiologia desconhecida (CID-280.96) sugere algumas possibilidades, tais como: a) a deficiência de ferro pode estar relacionada à perda de sangue pela hemorragia disfuncional, epistaxe, hemoptise; 
b) ser proveniente de um uso inadequado da medicação; c) uma deficiência de jejuno; d) desnutrição. Decerto, são situações que podem impedir a correção da dosagem de ferro.

Os exames necessários para confirmar ou não o diagnóstico de anemia ferropriva são: a) dosagem do ferro sérico; b) ferretina; c) hemograma; d) capacidade total de ligação do ferro (CTLF); e) saturação de transferrina.

A paciente tomou conhecimento do seu diagnóstico de "anemia ferropriva" há longa data, ou seja, em 1981, e apesar de ter sido orientada quanto à terapêutica medicamentosa, o resultado foi infrutífero.

De lá para cá, a configuração da clínica sofreu alterações apenas em relação à cronicidade.

\section{JUSTIFICATIVA}

A globalização dos meios de comunicação tem permitido acesso à informação de maneira ágil e intensa. Curiosamente com esta conquista, no entanto, perdeu-se o ritmo espaçado do tempo, através do qual se podia ter com cada paciente do hospital público uma interlocução mais particularizada. De fato, não há tempo hábil para ater-se à entrevista e ao exame clínico de forma pormenorizada devido a todos os compromissos assumidos, de modo que também é preciso calcular um tempo para cumprir as normas protocolares, como o preenchimento de formulários.

Este artigo tem primeiramente o intuito de chamar a atenção para o óbvio; isto é, à importância do diagnóstico diferencial. Por vezes, o que parece ser uma "perda" de tempo, na verdade, é um "ganho" de tempo uma vez que, com este procedimento, pode-se evitar a manutenção do transtorno comportamental ou minimização da probabilidade de acúmulo de experiências com tratamentos iatrogênicos. 
O segundo intento deste texto é mostrar a validade das discussões clínicas, por meio das quais especialistas de áreas afins possam colaborar com seu parecer, para que as questões que permeiam casos como este tenham respostas resultantes de uma análise clínica dos aspectos multifatoriais da pessoa que está enferma, e não apenas da enfermidade. No entanto, também é preciso lembrar que o consenso da avaliação deve ter como referência o transtorno manifestado e não a classificação da pessoa em si.

Assim, compete à psicologia contribuir para a elaboração de um diagnóstico psicopatológico, dando viabilidade à compreensão dos vezos que possam interferir na aderência ao tratamento, na exacerbação ou no acobertamento dos sintomas.

Com o conhecimento dos transtornos mentais e suas influências indesejáveis na evolução e no prognóstico, esta ciência torna factível a atuação e respectivas sugestões clínicas para a amenização dos efeitos perturbadores na organicidade e/ou no contexto sociopessoal e econômico do paciente.

Para obter os informes sobre as alterações psíquicas, sua etiologia e variáveis interferentes, o psicólogo examina minuciosamente as expressões verbais, gestuais, biótipo, bem como comportamentos perceptíveis ou detectados nos exames psicodinâmicos formais.

\section{HISTÓRIA}

A paciente é uma mulher branca, 52 anos, brasileira, estatura baixa $(1,50 \mathrm{~cm})$ solteira, católica, obesa $(75 \mathrm{~kg})$, nega etilismo e tabagismo. Completou o segundo grau e um curso profissionalizante em técnica de enfermagem.

No Hospital de Clínicas de Curitiba, seu primeiro internamento ocorreu em 1981. Desde então, sua trajetória constituise de várias internações e consultas em ambulatórios, que va- 
riam na especialidade da clínica ginecológica, devido à hemorragia disfuncional; clínica médica, em decorrência das indefinições gerais; clínica neurocirúrgica, pelo aparecimento de lombalgia e clínica hematológica, decorrente da anemia refratária e, conseqüentemente, politransfundida.

Em setembro de 1981, sua aposentadoria saiu oficialmente por não encontrar-se em condições físicas para a atividade produtiva, fato evidenciado nas freqüentes interrupções na jornada de trabalho. "Estou encostada pelo SUS" (sic.).

As manifestações eram de astenia, cefaléia, tontura, lombalgia, dores nas plantas dos pés, fadiga, sonolência, prostração, dispnéia, palidez e epistaxe.

Em todas as consultas, pelos exames clínicos, buscou-se uma justificativa para o quadro refratário; porém, nada foi detectado, uma vez que a paciente afirmava estar seguindo orientação medicamentosa e o sangramento era esporádico (epistaxe e ou hemorragia disfuncional, tipo menorréia).

Em janeiro, março, abril, junho, agosto e setembro de 1983, ocorreram internações no Hospital de Clínicas de Curitiba, com anotações específicas e coincidentes nos prontuários, realizadas por médicos diferentes e em situações diversas. Exemplificando:

(...) "perda anormal, descartar as causas da refratariedade"; "mal orientada no tempo e no espaço"; "bom estado geral"; "correspondente a um padrão de sinais e sintomas predominantemente psicológico"; "insiste em alta; não quer dar continuidade à investigação"; "astenia, cefaléia, tontura"; "exaustivamente investigada no sentido da causa da espoliação, sem nenhuma conclusão diagnóstica"; "depressão, encaminhamento psiquiátrico"; "assistente social não consegue con- 
tato com a família. Não aceitou a indicação nem aderiu à medicação específica."

É de uma família numerosa, composta por onze irmãos. Relata que todos são trabalhadores e que mantêm uma relação harmoniosa entre si. Diante deste comentário, pressupõe-se a viabilidade de algum telefone para comunicação. Porém, isto não ocorre. Frente a tal incomunicabilidade, subentende-se a existência de um vínculo inexigível ou desejo da paciente de tornar inexeqüível a comparação e verificação da verossimilidade dos relatos por ela mencionados.

Não se tem conhecimento dos reais motivos do não comparecimento dos familiares ao hospital. Conseqüentemente, a equipe não pode beneficiar-se deste veículo informativo nem usá-lo como elemento de apoio, observação e supervisão na realização das orientações e sugestões.

Atualmente - inverno do ano 2000 -, o quadro geral de queixas está marcado por cefaléia holocraniana, do tipo pontadas, com náuseas, dores nos pés e nas costas, dispnéia e voz rouca.

No exame físico, está com a pele e mucosas hipocoradas e sem edemas. Não tem deficiência de jejuno, para justificar a deficiência de ferro. Também foi eliminada a presença de hipotireoidismo. Além disso, seu exame citopatológico foi negativo para malignidade e, até o momento, não apresenta respostas satisfatórias com o uso de sulfato ferroso oral ou injetável.

A paciente foi novamente avaliada pela hematologia, de modo que se constatou o uso inadequado da medicação. Pela observação direta e constante da enfermagem, ao receber a medicação, verificou-se que a paciente dizia que depois iria ingeri-la; ou se fosse solicitado que tomasse naquele determinado instante, colocava-a na boca, sem engolir. Na seqüência, jogava pela janela ou escondia embaixo do travesseiro. 
Em relação ao exame psicopatológico, a paciente recusou-se a realizar testes psicológicos estruturais e dinâmicos, verbalizando que isto não seria bom para ela. Ao ser questionada quanto aos motivos desta percepção, reagiu com silêncio contínuo, que só interrompeu quando o teor do assunto direcionou-se para os aspectos da anemia.

Devido à resistência e ao desagrado em perceber o intuito da psicóloga de investigá-la com testes formais, esta apreciação sobre a paciente é resultante de duas entrevistas para avaliação do seu funcionamento psicodinâmico, obtido pelas informações pessoais, da personalidade pré-mórbida, antecedentes familiares, ocorrências psiquiátricas, performance social e acadêmica. Além disso, aconteceram discussões sobre o estudo de caso com o staff - médico, residente, enfermeiro, psicóloga, assistente social -, levantamento histórico do prontuário, incluindo informações sobre os exames, evolução clínica e comportamentos de todo o conjunto de internações e atendimentos ambulatoriais.

\section{RESULTADO DA AVALIAÇÃO PSICOPATOLÓGICA}

A paciente em questão manifesta alteração de apetite, sono, lentificação psicomotora, de raciocínio, desânimo, sentimento de menos-valia, sintomas que condizem com um Transtorno Distímico (DSM-IV. 300.04). Pode-se dizer que seu transtorno está correlacionado, como pano de fundo, às percepções, interpretações, julgamentos e reações pessoais em relação à vida e seus vínculos.

\begin{abstract}
A psicodinâmica de suas ações sugere passividade, medo de ser abandonada, dificuldade em assumir discordância, por receio de perder apoio. Compromete-se com atividades desagradáveis, por não se achar merecedora de escolhas.
\end{abstract}


Falta-Ihe confiança e sobra-lhe necessidade de proteção e cuidados, atitudes identificáveis como um Transtorno da Personalidade Dependente (DSM-IV. 301.6).

O agravante neste caso é que, junto a estes caracteres psicopatológicos, existem sinais e sintomas factícios; isto é, da Síndrome de Munchausen (Salton, 1982; Aguiar et al., 1990; Park \& Scerri, 1996).

\section{DISCUSSÃO}

Nesta hospitalização, confirmou-se sua postura enganosa, pelo controle direto, durante o horário da medicação. Foi possível observar a atitude provocativa da produção intencional de sinais e sintomas somáticos. No entanto, sua postura é doce, dependente, submissa, desamparada, aparentemente sem agressividade, que se apresenta em atitudes acobertadas e com hostilidade embutida nas atitudes passivo-agressiva.

Alguns fatos podem clarificar esta atitude simulada, tais como: a) "(...) no colégio interno, no horário de estudo estipulado era a primeira a concordar, mas, na realidade não estudava. Fugia." (sic.); b) no hospital não almoça, diz não ter apetite, mas é descoberta tentando sair para almoçar, sem avisar os responsáveis; c) aplica injeção nas crianças, mas, com a condição de que as mães acatem a sua "história"; isto é, cria um ritual para a aplicação: a cabeça da criança é coberta, abre-se à janela, a paciente entra, aplica a injeção e sai. Na seqüência, entra novamente como a titia bondosa e diz que o "homem velho" entrou pela janela porque ela não estava fazendo (algo do contexto e do interesse dos adultos) e que ele voltará de novo e a mãe não poderá ajudá-la. Trata-se de uma história fértil, com componentes que toldam o psiquismo da criança, quando menos ameaçador Ihe seria ouvir uma explicação real dos adultos. 
A afetividade da paciente está embotada. Tem dificuldade para refletir sobre os sentimentos; porém, manifesta tristeza e demonstra uma labilidade das emoções.

Ao mesmo tempo, às suas preocupações emocionais não está vinculado o fato de ser uma doente crônica, mesmo quando diz que "a doença incomoda, que tem sangramento e está há longa data em tratamento e internações". Pela expressão facial inalterada, não são convincentes seus comentários, ficando evidente que também não se atém a perdas, mas apenas ao colorido da sintomatologia.

Seu relato, por vezes, é incongruente. Ao ser indagada de modo mais específico, tem uma reação de ensimesmamento imediato, o qual é interrompido apenas por monossílabas - "sim...", "não..." - ou, até mesmo, por um simples gesto da cabeça.

Apresenta uma atitude de introspecção, timidez e esquiva. Contudo, na seqüência e ao receber atenção direta e continuada, seu discurso vago e superficial do início se transforma em prolixo, enriquecido espontaneamente com detalhes inconsistentes.

Possui uma memória que Ihe garante fazer um histórico detalhado de grande parte da sua vida. Entretanto, existem narrações com conteúdo divergente, conforme quem seja seu ouvinte. Exemplificando: na primeira versão, diz que mora sozinha e cuida da mãe. Na segunda versão, diz morar com a mãe, ter o próprio quarto, mas, mesmo dormindo com a luz acesa, quer e insiste em dormir no quarto da mãe, alegando ter medo de ladrões. Além disso, em outro momento relata que a casa localiza-se no mesmo terreno da irmã casada e dos seus sobrinhos e apesar de a mãe ter idade avançada, esta é independente. Conta que é a mãe quem decide sobre as questões relativas às finanças da casa, que participa de programas sociais e de atividades recreativas de um grupo de terceira idade. 
Há um outro relato discrepante: primeiro diz não ter hemorragias e, em seguida, diz ter hemorragias. Em outra informação, diz que toma os remédios exatamente como mandam. Depois, diz que os toma mas tem alguns que são amargos e ruins; estes, ela não toma. E por último diz que os toma, mas, quando sai, não leva junto.

$\mathrm{Na}$ análise de suas aquisições, conquistas e sonhos realizados, verifica-se que desistiu do sonho de criança de ser freira e que também largou o objetivo de ser enfermeira graduada porque os pais não concordavam que ela saísse de casa.

Observam-se em seu comportamento traços de submissão, passividade e de não-assunção do poder de decisão e responsabilidade pela escolha da própria vida, o que se evidencia no fato de não ter conseguido sair do ambiente familiar de origem e construir uma família própria; além de, em termos econômicos, viver apenas da pensão previdenciária e, profissionalmente, estar muito aquém do que desejou um dia.

Tais comportamentos de desistência e de deixar-se levar pelo desejo do outro geram na paciente ansiedade, raiva, tristeza e insegurança em ser descoberta nos seus sentimentos mais hostis. Talvez por não saber expressar e defender os sentimentos, mantém-se na queixa do desejo e não na sua realização. Então, acaba propendendo a um deslocamento das angústias psíquicas para o corpo, que se torna depositário de pensamentos e sentimentos não elaborados e, por isso, represados.

Além da anemia ferropriva, apresenta alterações somáticas, tais como: cólon irritável, gastrite, lombalgia, cefaléia tensional, o que ressalta a interferência negativa da psicodinâmica no follow up da paciente, ficando evidente não possuir alicerces 
bem estruturados, novos vínculos relacionais ou um objetivo maior que lhe sirva como sentido de vida. Assim, sente-se insatisfeita, sem razão de ser e sem uma garantia para estabelecer alguma relação de troca.

Pela cronicidade de seus sintomas, características de personalidade e pelo contexto socioeconômico, observa-se que a doença lhe serve como referência de identidade, "eixo da roda". Se for simplesmente retirado ou amenizado o quadro sem acompanhamento psiquiátrico, o restante da estrutura não se sustenta. Poderá entrar num outro tipo de desequilíbrio ou exacerbar comportamentos auto-agressivos, pelo exagero de condições médicas gerais, com conseqüências orgânicas, gerando impasses e contradizendo a conclusão diagnóstica, desencadeante de novas investigações e tentativas de investimentos na paciente. Com isto, é feita a manutenção do encadeamento patológico e de possíveis iatrogenias (Bulik et al., 1996).

Sua identidade de vida está centrada na doença. Ela não tem uma doença, ela está sendo a própria doença, que passou a ocupar a figura central e a identidade real enquanto a pessoa se tornou fundo "do quadro".

Nesta paciente, foi possível detectar alguns componentes de ocorrência que subsidiaram o diagnóstico da Síndrome de Munchausen; tais como: a) histórico de sucessivas hospitalizações; b) "tem um hospital da sua cidade, que atualmente não permite a entrada dela, porque pode pegar infecção" sic; c) "os médicos de lá estavam querendo Ihe dar injeção de água porque achavam que estava mentindo sobre os sintomas" sic; d) "sempre tem seringas e várias agulhas em casa, porque as cunhadas freqüentemente trazem; pois é ela que aplica injeções, quando alguém precisa" sic; e) "tem uma cunhada que trabalha como enfermeira no hospital. Esta, arranja amostra grátis para ela" sic; f) "com mais ou menos 17 anos, tomava remédio para dormir, na veia, muscular e oral" sic; g) "um médico orientou para que tomasse ferro. Não gostou da sugestão, então foi em 
outro. Pagou uma consulta particular, pediu remédio para emagrecer, conseguiu e começou a tomar esta fórmula" sic; h) "ocorrências de episódios em que ficava afônica na juventude, devido a dor constante de garganta" sic; i) "depois de adulta, aconteceram alguns episódios em que perdia o sentido" sic; j) apresentação atípica da evolução da doença; k) necessidade psíquica de obter cuidados, atenção e proteção, assumindo o papel de doente e buscando benefícios mesmo que não tenha méritos para tal; I) é atendente de enfermagem. Neste grupo, é possível apreender conhecimento e execuções diversas no bloqueio ou condução do tratamento; m) a fisiologia do seu organismo fala contra a ingestão de sulfato ferroso; n) o sangramento não é significativamente volumoso para se pensar numa perda de reservas; o) não há deficiência de absorção do sulfato ferroso que justifique a não assimilação; p) seu relato sobre a doença é fraudulento. Além disso, faz comentários mirabolantes, como já foi citado, em relação à história do "homem velho", por exemplo, indicando-lhe uma pseudologia fantástica; q) a necessidade psicológica de envolver-se e ser doente é palpável pela inexistência de incentivos externos para o comportamento; r) não recebe visitas.

\section{CONCLUSÃO}

Conclui-se que o tratamento da anemia ferropriva não era refratário, mas a paciente era quem estava sendo refratária a qualquer tentativa de ajuda mais eficaz e apaziguadora.

Os sintomas factícios não excluem a coexistência da doença hematopoiética. Por sua vez, a Anemia Ferropriva não exclui a coexistência de psicopatologias complexas, o que aponta a premência da associação de conhecimentos de áreas afins e complementares no percurso de seu tratamento. 
Enfim, a prática clínica permeou caminhos tortuosos, despertando a necessidade de uma revisão, para conferir ao diagnóstico uma evidência científica. Ao realizá-la, constatouse um número reduzido de artigos referentes à Síndrome de Munchausen. Mesmo assim, a comunicação deste relato talvez possibilite uma argumentação polêmica entre os profissionais de saúde e estimule uma expansão profícua do raciocínio clínico, para minimizar possíveis falhas e granjear resultados mais consistentes, despertando a necessária curiosidade científica, já que "não é suficiente curar os olhos sem a cabeça, nem a cabeça sem o corpo, assim como não basta curar o corpo sem a alma" (Sócrates).

\section{REFERÊNCIAS BIBLIOGRÁFICAS}

Aguiar, R. W.; Patric, F. \& Minotto. (1990). Síndrome de Münchausen: relato de dois casos. Rev. AMRIGS, 34(2), 119-23.

Bauer, M. \& Boegner, F. (1996). Neurological syndromes in factitious disorder. J. Nerv. Ment. Dis., 184 (5), 281-8.

Bulik, C. M.; Sullivan, P. F.; Fear, J. L. \& Pickering, A. (1996). A case of comorbid anorexia nervosa, bulimia nervosa, and Munchausen's syndrome. Int. J. Eat. Disord, 20(2), 215-8.

DSM-IV (1995). Manual diagnóstico e estatístico de transtornos mentais. $4^{\underline{a}}$ ed. Porto Alegre: Artes Médicas.

Park, A. J. \& Scerri, G. V. (1996). Munchausen's syndrome masquerading as necrotizing fasciitis. J. R. Soc. Med., 89(3), 170-1.

Salton, J. A. (1982). Síndrome de Munchausen: relato de um caso. Rev. AMRIGS, 26(3), 227-9. 